\title{
Nanostructured colloidal particles by confined self-assembly of block copolymers in evaporative droplets
}

\author{
Minsoo P. Kim and Gi-Ra Yi* \\ School of Chemical Engineering, Sungkyunkwan University, Suwon, South Korea
}

Block copolymers (BCPs) can create various morphology by self-assembly in bulk or film. Recently, using BCPs in confined geometries such as thin film (one-dimension), cylindrical template (two-dimension), or emulsion droplet (three-dimension), nanostructured BCP particles have been prepared, in which unique nanostructures of the BCP are formed via solvent annealing process and can be controlled depending on molecular weight ratio and interaction parameter of the BCPs, and droplet size. Moreover, by tuning interfacial property of the BCP particles, anisotropic particles with unique nanostructures have been prepared. Furthermore, for practical application such as drug delivery system, sensor, self-healing, metamaterial, and optoelectronic device, functional nanoparticles can be incorporated inside BCP particles. In this article, we summarize recent progress on the production of structured BCP particles and composite particles with metallic nanoparticles.

Keywords: block copolymer particle, nanostructure, hybrid particle

\section{What is Block Copolymer Particles?}

Block copolymers (BCPs) have been widely used as templates for the nanostructured materials, since the BCPs can self-assemble to a variety of nanoscale morphologies like spheres, cylinders, and lamellar depending on their composition, volume fraction and molecular weight (Bates and Fredrickson, 1990; Hawker and Russell, 2005; Xiong et al., 2009; Mai and Eisenberg, 2012). The key to the use of $\mathrm{BCPs}$ for the complex nanostructures is to control the orientation and lateral order of the microdomains in the thin films. For instance, the use of solvent vapor can induce orientation of the BCP nanostructures (Malenfant et al., 2007). Kim and Libera (1998) carried out the effect of solvent on the morphological evolution of BCPs in the thin-film, resulting in perpendicular orientation of asymmetric poly(styrene-block-butadiene-block-styrene) (SBS) after solvent evaporation (Kim and Libera, 1998). Cavicchi and Russell (2007) reported a significant improvement on the lateral ordering of poly(isoprene-block-lactide) (PI- $b$-PLA) by solvent annealing in the casting film (Cavicchi and Russell, 2007). Besides the solvent annealing method, the orientation of BCP nanostructures can be also controlled by changing the surface properties of the substrate or the gap between the two substrates (Huang et al., 1998). For example, the periodic patterned substrates have been used to enhance or control the lateral order of microdomains in BCPs (Figure 1A) (Bita et al., 2008). Furthermore, various frustrated nanostructures inside confined geometry could be developed as shown in Figures 1B-D (Yu et al., 2007, 2006; Li et al., 2013). For one-dimensional (1D) confined geometry, it has been well known that perforated lamella phase can be formed instead of gyroid or bicontinuous phase (Figure 1B) (Koneripalli et al., 1995; Nikoubashman et al., 2014; Zhang et al., 2015a). In the case of cylindrical pores in anodized alumina oxide (AAO) membranes, various helical 


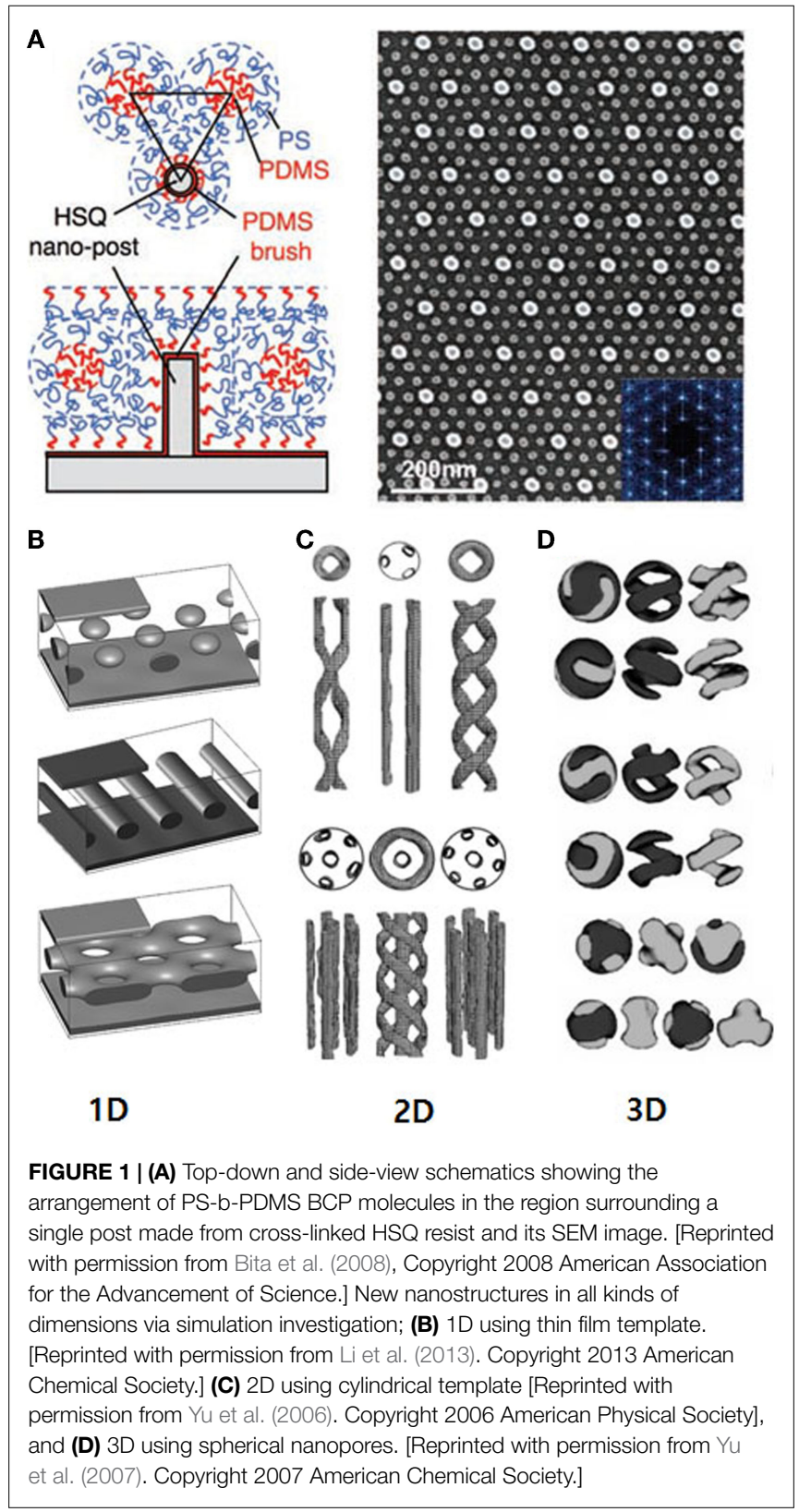

structures were observed and they have been used as confining geometries (Lambooy et al., 1994; Dauphas et al., 2004; Wu et al., 2004; Xiang et al., 2004; Maiz et al., 2014; Hou et al., 2015). According to the theoretical prediction, more unusual morphologies like single helices, double helices, and meshes could be produced as shown in Figure 1C (Li and Wickham, 2006; Li et al., 2006; Yang et al., 2012; Bae et al., 2013; Xu et al., 2014; He et al., 2015; Zhang et al., 2015b; Zuo et al., 2015).

Likewise, in the case of three-dimensional (3D) confining geometries such as spheres, multi-shell, or onion-like structures or other morphologies as shown in Figure 1D could be developed (Yu et al., 2007). The nanostructures has been proved simulationally (Yu et al., 2007; Hao et al., 2014) and experimentally (Higuchi et al., 2012, 2008; Xu et al., 2015). These are practically important in a broad range of applications including the production of impact-resistant polymers, composite materials, catalytic supports, coatings, and adhesives (Sundberg and Durant, 2003). For instance, dyed multi-shell particles have been used in high-density 3D optical data storage and security data encryption (Pham et al., 2004). Most of core-shell structured colloids have been employed in bio-application such as drug delivery and biosensor (Otsuka et al., 2003; Wang et al., 2011; Robb et al., 2012; Yu et al., 2014; Louage et al., 2015). The researchers have prepared the colloidal particles composed of the assemblies of spherical polymeric micelles, which have been employed to study stimuli-reactive delivery or sensor system. In addition, hollow particles have been used in bio-application such as self-healing. Mohwald group reported that hollow polymer particle with onionlike nanoshell structure can be employed in bio-related application such as nanocapsule and self-healing (Sukhorukov et al., 2005; Grigoriev et al., 2009; Delcea et al., 2011; Latnikova et al., 2012). Structured spheres with periodic radial variation of the refractive index have attracted much attention due to their potential uses as spherical dielectric resonators in cavity quantum electrodynamics, optical switches, and limiters (Babin et al., 2003; Gourevich et al., 2006; Petukhova et al., 2008; Zhang et al., 2008a; Burlak et al., 2012). Interestingly, by tuning the surface property of the BCP particles, ellipsoid-structured particles from spherical particles can be created (Deng et al., 2013; Klinger et al., 2014). The shape-controlled particles can be applied in the fields such as multi-responsive materials, optical device, and biomedical delivery device.

Furthermore, incorporating functional materials such as metal or semiconductor into the nanostructured BCP microsphere can produce novel inorganic nanostructures with new characteristics, which depend on their spatial and size distribution (Jeon et al., 2009; Connal et al., 2012; Ku et al., 2013). The composite BCP microspheres have been prepared by selective interaction between one block of the $\mathrm{BCP}$ and polymer-capped nanoparticles or infiltration of inorganic precursors into the one block. For example, Ku et al. (2013) have fabricated hybrid BCP-quantum dot (QD) microspheres by spatially isolating different-colored QDs into core-blocks of the BCP micelles, which can control Förster resonance energy transfer (FRET) between QDs, resulting in formation of multicolor emission colloidal particles.

This review focuses mainly on how BCP colloidal particles could be formed with unique internal structures and then describes how nanoparticles could be incorporated or decorated. Finally, we will discuss remaining issues or problems for future applications.

\section{Synthesis of Structured Block Copolymer Particles}

Structured BCP particles can be prepared synthetically using mini-emulsion polymerization method (Landfester, 2001a, 2009; Rao and Geckeler, 2011). In the method, two different kinds of monomers are dispersed in aqueous media with surfactants to stabilize the interface between the monomers and water. Polymerization is performed by an initiator dispersed in the aqueous phase, resulting in formation of random BCPs. More effective method to fabricate the particles has been 
developed using radical polymerization (Smulders and Monteiro, 2004; Landfester, 2009; Wang and Zhang, 2012). For example, poly( $n$-butylacrylate-block-styrene) (PnBA- $b$-PS) particles were prepared by radical emulsion polymerization using a structural control agent (e.g., 1,1-diphenylethylene) or reversible additionfragmentation chain-transfer (RAFT) agent, which is dispersed in the aqueous solution. Landfester et al. demonstrated that the particles, which have core-shell or hollow structures, can be used in the bio-application such as nanocapsules for drug delivery or self-healing materials (Landfester, 2001b, 2006; Landfester and Mailander, 2013; Lv et al., 2013; Vimalanandan et al., 2013). Moreover, hollow structured particles can be produced by layer-by-layer (LBL) assembly on colloidal particles as a template (Pastoriza-Santos et al., 2001; Coustet et al., 2014). The LBL technique is based on the consecutive assembly of oppositely charged polymer layers on a preformed charged spherical colloidal particle. After LBL assembly, the cores of the particles can be removed by selective dissolution or calcination, followed by formation of hollow particles. Mohwald et al. reported that the hollow particles were prepared by LBL assembly using charged polymer such as poly(diallyldimethylammonium chloride), poly(allylamine hydrochloride), or poly(styrene sulfonate) onto the charged silica or PS particles (Caruso et al., 1998a,b; Caruso and Mohwald, 1999; Shchukin and Mohwald, 2006). After removal of the cores in the particles, the hollow structured particles were obtained, which can be applied as biomaterials such as drug delivery carriers or self-healing (Peyratout and Dahne, 2004; Ma et al., 2005; Rivera Gil et al., 2008; Delcea et al., 2011; Latnikova et al., 2012; Yan et al., 2014). Although the structured particles prepared by mini-emulsion polymerization or LBL technique have narrow size distribution, the methods have been limited to control the inner nanostructure of the BCP particles.

On the other hand, BCP particles can be prepared directly from polymer solution by filling lithographically prepared voids and removing the template such as AAO template ( $\mathrm{Wu}$ et al., 2004; Wang et al., 2008; Mei et al., 2011; Mei and Jin, 2013; Chu et al., 2014). Generally, a template is immersed in polymer solution during a constant time and then the template is picked up from the solution, resulting in formation of BCP nanotubes. After annealing of the BCP nanotubes, the template is selectively removed by etchant such as $\mathrm{NaOH}$ to release the nanotubes. Some groups demonstrated that the BCP particles were prepared by the templating method, which had spherical shape after exposure to neutral solvent for the BCP. Furthermore, mesoporous-structured $\mathrm{BCP}$ particles were fabricated by swelling of the BCP after exposure to a selective solvent which prefers one of the BCP (Mei et al., 2011; Mei and Jin, 2013).

Emulsion-encapsulation and solvent-evaporation method have been widely used for BCP particles, in which the polymer solution was dispersed in a non-solvent and the organic solvent inside emulsion was evaporated. Similarly, Thomas et al. (1990) experimentally demonstrated the formation of BCP particle using aerosol droplets as the confined geometry. Generally, BCP solution is atomized with an air jet atomizer, resulting in production of aerosol droplets. In nitrogen carrier gas, the droplets are transported to a heated tubular reactor where they are dried and heated for several seconds. After the droplets are cooled, the dried BCP particles are finally collected. The method using the aerosol droplets would produce small particles ranging from submicrometers to a few micrometers after completely removing the solvent from the droplets ( $\mathrm{Lu}$ et al., 1999). Later then, various structured BCP particles were prepared from aerosol droplets where poly(styrene-block-4-vinylpyridine) (PS-b-P4VP) or triblock copolymer with poly(3-triethoxysilyl)propyl block were included (Zhang et al., 2008a,b, 2010a; Rahikkala et al., 2013). However, the nanostructures inside the BCP particles could not reach to equilibrium state or significantly overlapped between the neighboring domains because of fast removal of the solvent from the aerosol droplets.

In case of using emulsion droplets as confining geometries (Figure 2A), well-defined BCP particles can be prepared by the evaporationinduced microphase separation of BCPs. BCPs are dissolved in organic solvent, which is not miscible to water and then dispersed in aqueous solution containing surfactant. After slowly solvent evaporation from the droplets, the structured BCP particles are produced. When symmetric BCPs were assembled, onion-like structure was observed and other morphologies were also obtained by adding homopolymers as shown in Figure 2B (Jeon et al., 2007). The microdomains of spheres, cylinders, and lamellae were structured in concentric arrangements due to the external spherical confinement provided by the emulsion droplets. Yu et al. (2007) reported the morphologies in BCP particles by Monte-Carlo simulations. It was shown that the morphologies in the BCP particles were dependent on the equilibrium spacing of the BCP structures in the bulk films $\left(L_{0}\right)$ and the diameters of the microspheres $(D)$ as shown in Figure 2C. Moreover, interfacial tension was controlled using a mixture of surfactants, for example, poly(styrene-block-ethyleneoxide) (PS- $b$-PEO) and poly(butadiene-block-ethylene oxide) (PB- $b$-PEO) (Jeon et al., 2008). As shown in Figure 3, single type of surfactant produced onion-like spherical particles, but mixture of surfactants produced ellipsoidal particles with stacked lamellae nanostructures.

Another method to fabricate the structured BCP particles directly from polymer solution is using re-precipitation (Yabu et al., 2005; Li et al., 2010; Yabu, 2013). The polymer solution is slowly added to a large amount of poor solvent for the polymer, which is miscible with the good solvent. After evaporation of good solvent into the polymer solution, structured BCP particles can be produced. To selectively evaporate the good solvent, its boiling point should be lower than that of the poor solvent. For example, Higuchi et al. prepared the nanostructured BCP particles by controlled precipitation from a tetrahydrofuran (THF)-water mixture (Higuchi et al., 2008). Through gradual evaporation of THF in the solvent mixture with symmetric poly(styrene-blockisoprene) (PS-b-PI), various nanostructures in the particles were produced.

Generally, the nanostructures of BCP in thin film have been developed during thermal annealing (Bates and Fredrickson, 1990; Winey et al., 1994; Park et al., 2003; Tang et al., 2004; Hawker and Russell, 2005; Xu et al., 2005; Ahn et al., 2009; Marencic and Register, 2010; Lee et al., 2011; Bai et al., 2013) above glass transition temperature $\left(T_{\mathrm{g}}\right)$ or solvent annealing (Li et al., 1996; Zhao et al., 2004; Kim et al., 2006; Bang et al., 2007; Cavicchi and Russell, 2007; Jung and Ross, 2007; Malenfant et al., 2007; Zhang 
A
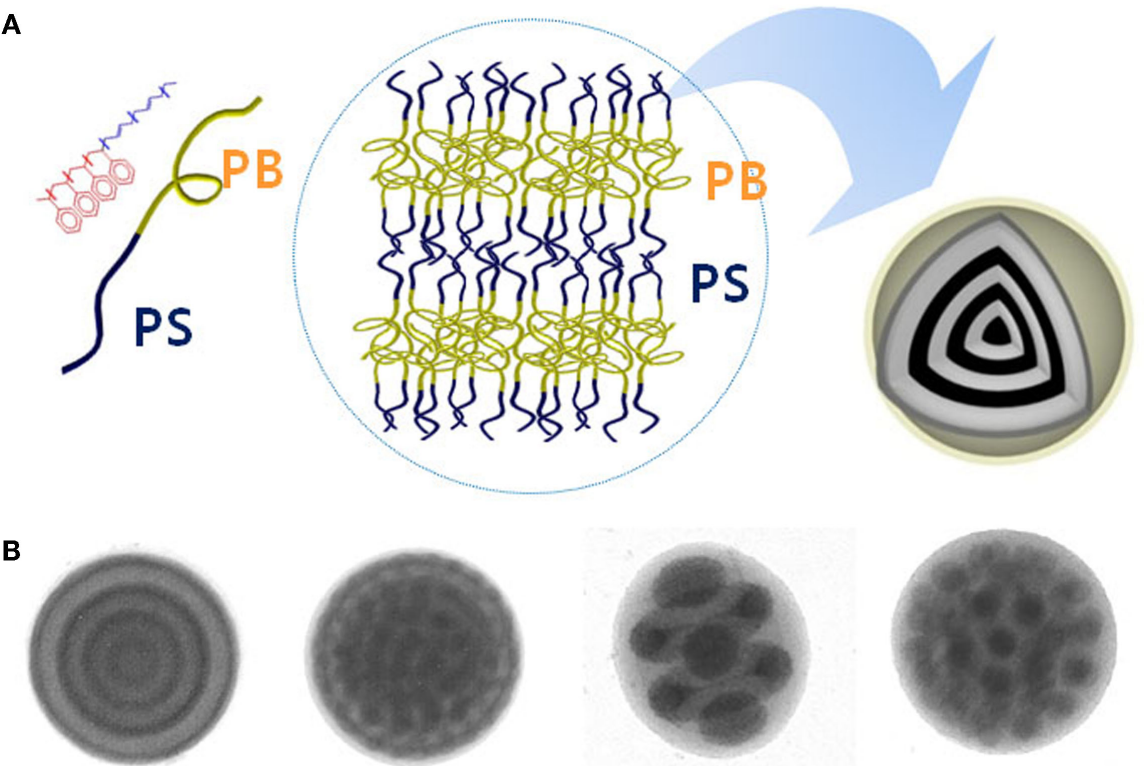

Lamellar (L) Perforated Lamellar (PL)

Cylinder (C)

Sphere (s)
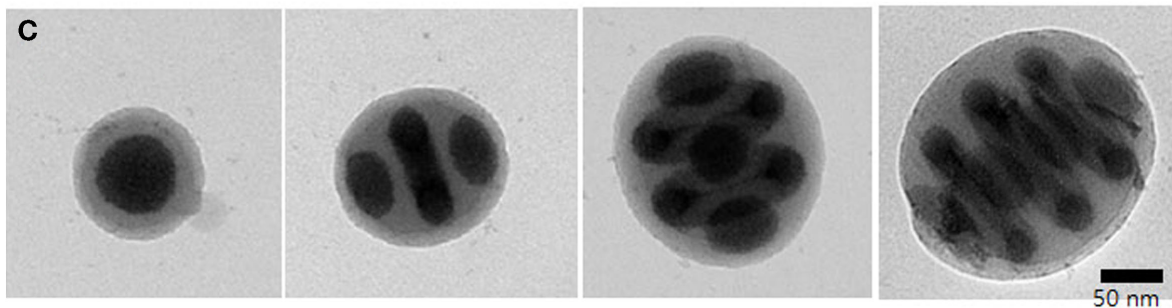

FIGURE 2 | 3D confinement effect of BCPs in emulsion droplet. (A) Schematic illustration of preparation of PS-b-PB BCP particles with nanostructures in emulsion droplets. Morphological transition of the BCP particles depending on (B) volume fraction of the BCP and (C) droplet size. [Reprinted with permission from Jeon et al. (2007). Copyright 2007 American Chemical Society.]

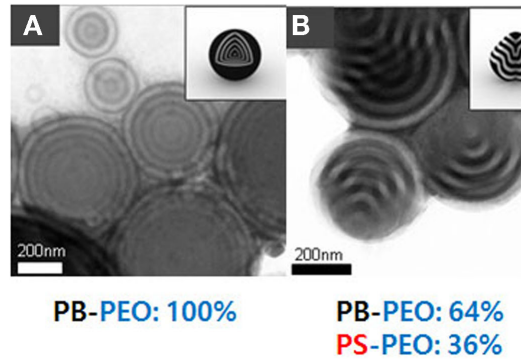

FIGURE 3 | TEM images of PS-b-PB colloidal particles depending on the volume ratio $\left(f_{\mathrm{s}}\right)$ of PS block in the mixed surfactant of PS-b-PEO and PB-b-PEO: (A) particles with onion-like morphology for $\boldsymbol{f}_{\mathbf{s}}=\mathbf{0}$. (B) "Tulip-bulb" particles for $f_{\mathrm{s}}=0.36$.

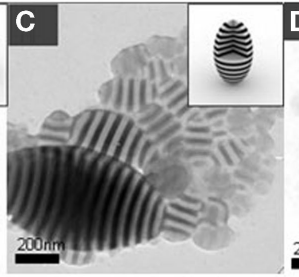

PB-PEO: $54 \%$ PS-PEO: $46 \%$

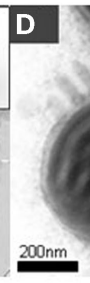

PB-PEO: $23 \%$

PS-PEO: $77 \%$

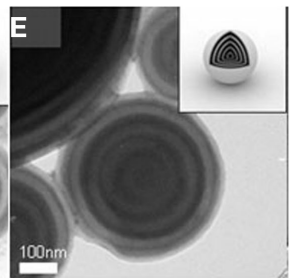

PS-PEO: $100 \%$ et al., 2007; Chang and Lo, 2011; Chu et al., 2014; Kao et al., 2014) in the presence of solvent below $T_{\mathrm{g}}$. Solvent annealing uses solvent vapor to increase chain mobility of BCP unlike thermal annealing in which the film are heated above $T_{\mathrm{g}}$. Similarly, the nanostructures in the BCP particles can be accomplished by solvent annealing method (Li et al., 2010; Chi et al., 2011; Deng et al., 2013; Yabu, 2013; Jin and Fan, 2014) because the particles have been
(C) Prolate particles for $f_{\mathrm{s}}=0.46$. (D) "Tulip-bulb" particles with inverted structure of the particles in (B) for $f_{s}=0.77$. (E) Onion-like particles for $f_{\mathrm{s}}=1$. [Reprinted with permission from Jeon et al. (2008). Copyright 2008 Wiley-VCH.]

prepared from polymer solution. The morphological evolution of the BCP particle during solvent annealing has been reported theoretically and experimentally. Chi et al. studied solvent-induced self-assembly of BCPs under confinement via simulation (Chi et al., 2011). The self-assembled internal morphologies such as stacked lamellae, hexagonally packed cylinders, stacked toroids, or helices were predicted as functions of solvent-polymer interaction 
and the monomer concentration. Experimentally, Russell group demonstrated solvent-driven morphology of BCP particles using re-precipitation method from THF/water mixture (Li et al., 2010). They used a symmetric PS- $b$-PI BCP and chloroform for evolution of the BCP nanostructures. Since chloroform is a good solvent for both blocks, it can swell and anneal the BCP particles, resulting in formation of onion-like nanostructures. Upon the extended annealing, the nanostructures are evolved to cylindrical morphology and finally core-shell spherical structure.

Recently, microwave annealing approach have been developed for rapidly inducing self-assembly of BCP, by which highly ordered patterns were achieved within $3 \mathrm{~min}$ (Zhang et al., 2010b; Mokarian-Tabari et al., 2014). The method is based on simultaneously solvent-driven and thermal-driven mechanism by adsorption of microwave radiation into BCP chains, resulting in generation of $\mathrm{BCP}$ nanostructures in minutes. The nanostructure of BCP particles can be also created by microwave annealing method. Higuchi et al. examined morphological transitions of PS$b$-PI BCP particles depending on experimental conditions such as temperature and time during microwave annealing (Higuchi et al., 2013). Even though the BCP particles are dispersed in aqueous solution, which has a higher dielectric constant and absorb most of microwave radiation, a small amount of the radiation can evolve the BCP nanostructures.

In addition, it is possible to change the particle shape from sphere to ellipsoid by tuning surface property of the BCP particles. Jintao group prepared reversible transformed BCP particles by solvent-adsorption annealing (Deng et al., 2013). In the article, poly(vinyl alcohol) (PVA) was used as a surfactant, which is a critical role in determining the particle shape, and chloroform, which is a good solvent for both blocks was used to swell and anneal the ellipsoid particles to spherical particles with onion-like structures. Moreover, they reported to fabricate polymeric Janus particles with hierarchically structures by phase separation of PS- $b$-P4VP and homopolymer poly(methyl methacrylate) (PMMA) binary blend (Deng et al., 2014). The Janus particles were tuned by varying copolymer composition, blending ratio, solvent selectivity, and particle size and reversibly transformed by solvent-adsorption process. Hawker group developed a new strategy to prepare ellipsoid BCP particles using modified surfactants (Jang et al., 2013; Klinger et al., 2014). Jang et al. (2013, 2011) prepared PS-bPI terminated Au-core/Pt-shell nanoparticles as a surfactant for poly(styrene-block-2-vinylpyridine) PS-b-P2VP droplets. Since the nanoparticles preferentially adsorb at the emulsion interface and modify the interfacial interactions between PS- $b$-P2VP domains, the BCP droplets can be transformed to ellipsoid particle with striped nanostructure. Besides the nanoparticle surfactant, they chemically modified cetyltrimethylammonium bromide (CTAB) to hydroxyl-terminated CTAB (CTAB-OH). Although CTAB has a good affinity to PS, CTAB-OH prefer to P2VP chains, which can be produced onion-structured particles with P2VP as the outermost layer. When the fraction ratio of $\mathrm{CTAB}-\mathrm{OH}$ and $\mathrm{CTAB}$ was between 0.7 and 0.8 , ellipsoid particle was prepared with an internal nanostructure of stacked lamellae morphology.

Briefly, those factors to control the morphology in the BCP particles can be summarized as follows; the effects of the molecular weight and concentration of the BCP solution, the effect of the ratio of the particle diameter to the BCP structure period $\left(D / L_{0}\right)$, the effect of the ratio of the good solvent to the poor solvent for the BCP on the microphase separation within the microspheres, and the effect of the interfacial tension between BCP solution and surfactants.

\section{Composite Block Copolymer Particles}

Block copolymer particles can be hybridized with functional inorganic, semiconductor, or metallic materials, to produce composite or hybrid BCP particles. There have been several different strategies for such a hybrid BCP particles, which can be categorized into chemical approach (MacLachlan et al., 2000; Manners, 2001, 2007; Korczagin et al., 2004; Whittell et al., 2011; Hudson et al., 2014; Zoetebier et al., 2015) using polymerization of metal-containing monomers and physical approach (Spatz et al., 1998; Kane et al., 1999; Tsutsumi et al., 1999; Lopes and Jaeger, 2001; Sohn and Seo, 2001; Boontongkong and Cohen, 2002; Bockstaller et al., 2003; Misner et al., 2003; Chiu et al., 2005; Kim et al., 2005; Yoo et al., 2010; Jang et al., 2011; Lim et al., 2011; Paek et al., 2011; Janczewski et al., 2014) such as ex situ and in situ approaches. The chemical approach is to use metal-containing monomer units. After living free-radical polymerization or ring-opening polymerization of the unit, metallopolymer can be produced. For example, Manner group reported a synthetic method to produce organo-metallic polymer. They performed ring-opening polymerization of spirocyclic silaferrocenophane as a monomer, resulting in formation of cross-linked $\mathrm{Fe}$ containing polymer (MacLachlan et al., 2000). Moreover, they prepared fluorescent nanorod particles by micelle assembly of poly(ferrocenyldimethylsilane-block-(dimethylsiloxane-randommethylvinylsiloxane)) (PFS- $b$-(PDMS- $r$-PMVS)), which was synthesized by anionic polymerization (Hudson et al., 2014). The vinyl groups were then functionalized by photoinitiated hydrothiolation (thiolene-click reactions) with thiol reagents, providing primary hydroxyl or amino groups to which functional dyes may be attached. Vancso group reported a method to synthesize poly(ferrocenylsilane-block-methacrylate) (PFS$b$-PMMA) by combined living radical polymerization. PFS was synthesized by anionic polymerization and PMMA was sequentially synthesized by ATRP, followed by production of PFS- $b$-PMMA (Korczagin et al., 2004). Although the chemical approach is to use inorganic precursor-containing monomers, it remains a challenge that the particles should be reduced as metal-polymer particles.

On the other hand, the physical approach to achieve hybrid BCPs is to use interaction between one block of BCPs and polymer ligands attached on the surface of NPs (ex situ method) or attraction between one block of BCPs and inorganic precursor (in situ method). The ex situ method is based on non-covalent interaction (e.g., van der Waals, $\pi-\pi$ interactions or hydrogen bonding) or covalent linkage between each block and surface ligand of the NPs. For example, Bockstaller et al. (2003) reported alkanethiol-capped $\mathrm{Au}$ NPs localized at the interface between a symmetric poly(styrene-block-ethylene copropylene) (PS- $b$-PEP). Kim et al. (2005) studied PS-coated Au NPs self-assembled within 

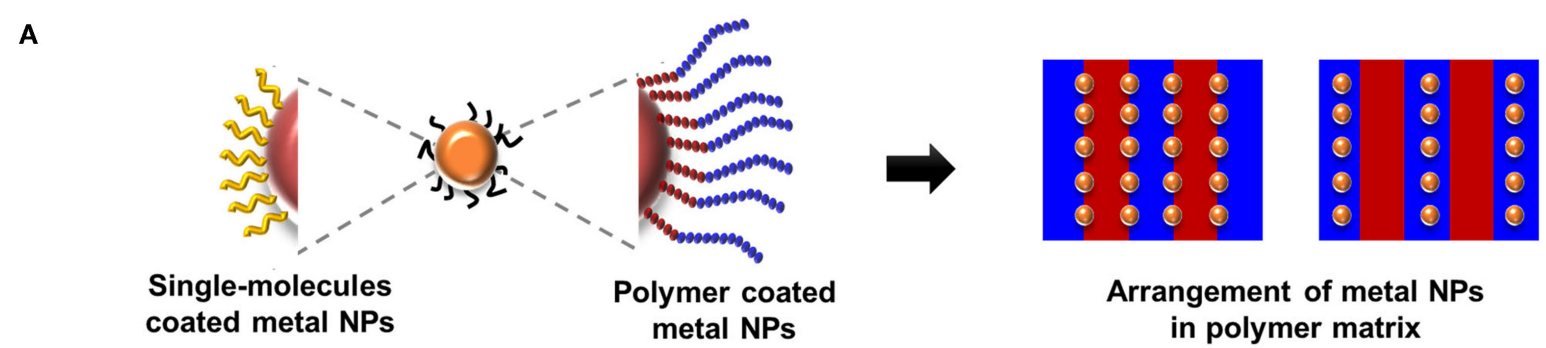

Arrangement of metal NPs in polymer matrix
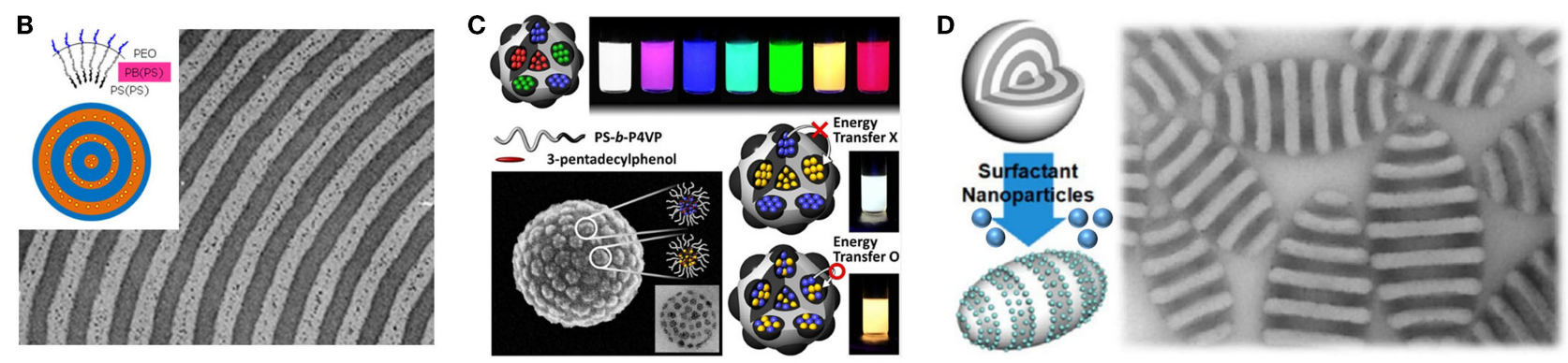

FIGURE 4 | (A) Schematic illustration of preparing hybrid BCP particles through ex situ method. (B) Cross-sectional TEM image of hybrid particles of PS-b-PB and PS-coated Au particles with PB-b-PEO (bottom left) and with PS-b-PEO stabilizer (bottom right). [Reprinted with permission from Jeon et al. (2009).

Copyright 2009 American Chemical Society.] Lighter layers are the PS domains.
(C) Multicolor emitting PS-b-P4VP particles with different types of quantum dots. [Reprinted with permission from Ku et al. (2013). Copyright 2013 Wiley-VCH.] (D) Ellipsoidal PS-b-P2VP particles using PS-b-PI terminated Au NPs as a surfactant [Reprinted with permission from Jang et al. (2013). Copyright 2013 American Chemical Society.]
PS- $b$-P2VP. They found that the addition of NPs increased the effective volume fraction of the PS block and thus induced a lamellar-to-cylindrical phase transition. However, due to the steric hindrance between the core-shell type NPs and BCP chains, the density of NPs within the templates is expected to be much lower compared to the in situ approach. In addition, if the surface modification of NPs is necessary for such precise control, the intrinsic properties of NP can be deteriorated by increase in defect sites on the surface of NPs. The in situ method is based on electrostatic attraction between $\mathrm{BCP}$ chains and inorganic precursor. Generally, this approach has used $\mathrm{Au}, \mathrm{Pt}, \mathrm{Pd}$, and $\mathrm{Ag}$ as inorganic precursors and poly(styrene-block-acrylic acid) (PS- $b$-PAA), and PS- $b$-P2VP as BCPs. For example, Chai et al. reported to fabricate linear metallic patterns using PS- $b$-P2VP (Chai et al., 2007). Since $2 \mathrm{VP}$ units of $\mathrm{P} 2 \mathrm{VP}$ have been protonated under acidic condition, anionic metallic precursor (e.g., $\mathrm{AuCl}_{4}^{-}, \mathrm{PdCl}_{4}^{2-}, \mathrm{PtCl}_{4}^{2-}$ ) interacted with the protonated 2VP units by electrostatic attraction. After their self-assembly on silicon substrate and metallization through chemical reduction, metallic patterns were produced, which can be extended toward increasing the conductance of the metallic nanowires and investigating the response of wire resistance to the environment for chemical and biosensing applications. In this section, we focus on ex situ and in situ approaches to produce hybrid BCP particles with nanostructures.

\section{Ex Situ Method}

The ex situ approach exploits the cooperative self-organization of pre-formed nanoparticles (NPs) and BCPs. The strategy for incorporating and controlling the location of NPs in a BCP or polymer blend involves tuning the surface properties of the NPs by functional polymer ligands, which play a critical role in particle location (Figure 4). The ex situ method of controlling the structural characteristics of the sequestered component uses cooperative self-organization of pre-made NPs and BCPs. Through this method, NPs with desired size and shape coated with oligomers or polymers can be incorporated in the polymer matrix. Once phase separation of the copolymer has occurred, the NPs can be confined in one of the segregated domains. Some have studied the control of the position in polymer matrix after coating the surface of the NPs using organic molecules (Zhao et al., 2009; Li et al., 2011). For example, Jeon et al. (2009) have prepared hybrid onionlike PS-b-PB particles containing PS-coated Au NPs. Since Au NPs were sufficiently covered with PS ligands, all Au NPs were located near the center of PS domain as shown in Figure 4B. Ku et al. (2013) have fabricated multicolor emitting hybrid PS- $b$-P4VP particles using QDs; white-color emitting particles were produced when two different types of QDs were independently incorporated into isolated PS- $b$-P4VP micelles, while orange-color emitting particles when the QDs were concurrently incorporated into the same micelles (Figure 4C). Furthermore, the NPs incorporated into the BCP particles could be used as a surfactant, which resulted in tuning the particle shapes. Jang et al. (2013) have reported that the spherical BCP particles could be changed to ellipsoidal particles when polymer-coated Au NPs were used as a surfactant which tunes the interfacial tension of the particles (Figure 4D). In addition, Ku et al. $(2014,2015)$ have investigated the effect of NP size and aspect-ratio (AR) to control the interfacial tension of the BCP particles. They prepared oleylamine-capped Au NPs with different size or oleic acid/oleylamine-capped $\mathrm{CuPt}$ nanorods with different $\mathrm{AR}$, which was used as a surfactant for the BCP particles. Using supramolecular assembly between the prepared NPs and the BCP domain into the emulsion droplets, the authors 


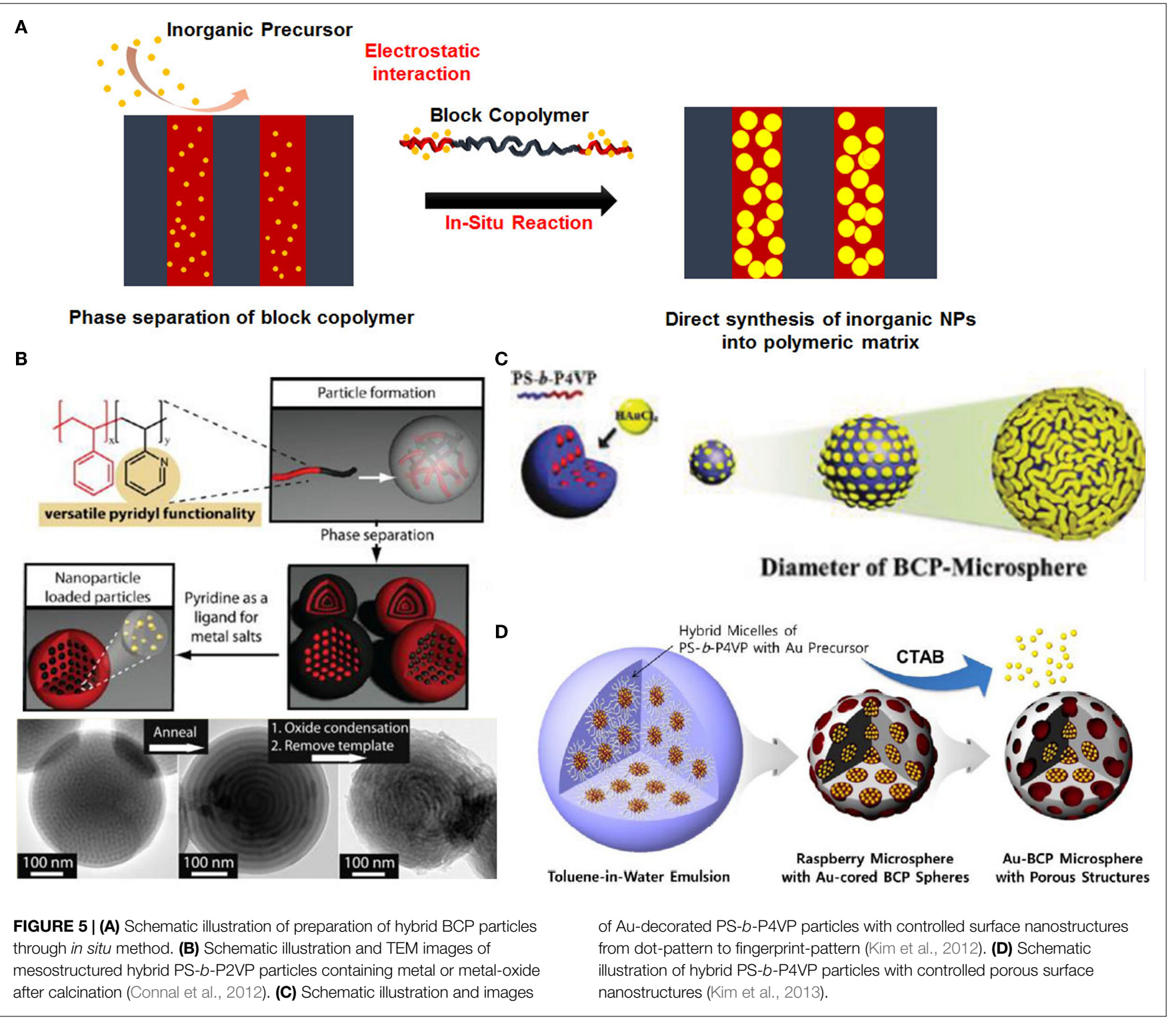

demonstrated that convex-lens shaped PS- $b$-P4VP particles with defect-free and vertically ordered porous channels were created by tuning the interfacial tension.

Since the ex situ approach utilizes pre-made NPs that have desired size, shape, and uniformity, this approach is suitable for several applications that require inorganic and/or metallic NP with well controlled size and uniformity, for example, optoelectronic device (Ameri et al., 2009; Leventis et al., 2010; Yang et al., 2011; Liu, 2014), responsive sensor (Paek et al., 2011, 2014; Lee et al., 2013a; Yang et al., 2013), and catalyst (Campelo et al., 2009). Furthermore, the location of NPs within BCP matrix can be easily and precisely controlled by tailoring the surface properties of the NPs.

\section{In situ Method}

Another simple concept to incorporate the NPs into polymeric nanostructures is in situ method, followed by a chemical reduction step to obtain metallic nanoparticles (Figure 5). The in situ approach is that NPs are directly synthesized within a BCP domain from metal precursors.

In that case, a specific and strong interaction between the precursors and the BCPs is required to guarantee the incorporation of metal precursors into the domain. In the in situ approach, preformed micelles of BCPs containing metal precursors are used as nanoreactors to synthesize NPs selectively in BCPs. Due to its chemical affinity, the salt selectively infiltrates the hydrophilic copolymer domain. The NPs are then form selectively within the precursor-loaded domains upon reduction. The targeted types of application mainly depend on the properties and functionality of the hybrid materials, which are determined by their chemical composition as well as morphological and structural parameters, for example, catalyst (Shastri and Schwank, 1985a,b; Wan et al., 1999; Bonnemann et al., 2000; Guczi et al., 2003), sensing device (Lee et al., 2013b; Choi et al., 2014), and metamaterials (Soukoulis and Wegener, 2011; Ramahi et al., 2012; Sheikholeslami et al., 2013). 
Among the BCPs, polystyrene- $b$-poly (vinylpyridine) (PS- $b$ PVP) BCP has been widely used for preparing hybrid materials. This is because the nitrogen atoms in PVP block have unpaired electrons which interact strongly with metal precursor (Hayward et al., 2005; Chai et al., 2007). For example, Connal et al. (2012) have fabricated hybrid PS- $b$-P2VP particles by selectively infiltrating $\mathrm{Au}$ precursors $\left(\mathrm{HAuCl}_{4}\right)$ into the $\mathrm{P} 2 \mathrm{VP}$ domain. In addition, they prepared mesoporous metal-oxide particles from PS- $b$-P2VP particles containing metal-oxide precursors after removing the BCP template by calcination. Furthermore, hybrid BCP particles with controlled surface nanoastructures also have been reported (Kim et al., 2012, 2013). The prepared spherical BCP particles using spherical PS- $b$-P4VP micelles were investigated the surface nanostructures from dot pattern to fingerprint pattern depending on the size of the BCP particles after infiltrating Au precursors into the BCP particles. In addition, we prepared dot-pattern hybrid BCP particle using spherical PS- $b$-P4VP micelles with Au precursors. After removing Au precursor into the P4VP domain, we produced hybrid BCP particles with porous surface which was controlled by tuning the amount of the Au precursors into the P4VP unit.

\section{Summary and Outlook}

Using BCPs in confined geometries such as aerosol or emulsion droplets, many nanostructured BCP particles have been prepared after solvent annealing process. They show a variety of new nanostructures due to confinement effect and interfacial properties. According to the theoretical prediction, however, much more nanostructures could be developed by more precise control of particle size and interfacial properties. Complex architecture of BCP such as star shape or multi-BCPs would also be applied into these BCP particles. Recently, these colloidal particles were functionalized by combination of various nanoparticles. Nanoparticles were mixed with BCP before particles formation (ex situ method) or precursors for nanoparticles were added after preparing BCP particles (in situ method). As an alternative route, nanopores were produced by removing selectively one of blocks, using molecular

\section{References}

Abate, A. R., Kutsovsky, M., Seiffert, S., Windbergs, M., Pinto, L. F. V., Rotem, A., et al. (2011). Synthesis of monodisperse microparticles from non-newtonian polymer solutions with microfluidic devices. Adv. Mater. 23, 1757-1760. doi:10. 1002/adma.201004275

Ahn, H., Ryu, D. Y., Kim, Y., Kwon, K. W., Lee, J., and Cho, J. (2009). Phase behavior of polystyrene-b-poly(methyl methacrylate) diblock copolymer. Macromolecules 42, 7897-7902. doi:10.1021/la702745w

Ameri, T., Dennler, G., Lungenschmied, C., and Brabec, C. J. (2009). Organic tandem solar cells: a review. Energy Environ. Sci. 2, 347-363. doi:10.1039/ b817952b

Babin, V., Garstecki, P., and Holyst, R. (2003). Multiple photonic band gaps in the structures composed of core-shell particles. J. Appl. Phys. 94, 4244-4247. doi:10.1063/1.1604932

Bae, D., Jeon, G., Jinnai, H., Huh, J., and Kim, J. K. (2013). Arrangement of block copolymer microdomains confined inside hemispherical cavities. Macromolecules 46, 5301-5307. doi:10.1021/ma4009324

Bai, P., Kim, M. I., and Xu, T. (2013). Thermally controlled morphologies in a block copolymer supramolecule via nonreversible order-order transitions. Macromolecules 46, 5531-5537. doi:10.1021/ma401033w templates or selective swelling process, which were then backfilled with other functional materials. Due to their unique nanostructure, these particles would be useful in various nanophotonic applications when the particles were functionalized with optically active materials. Particularly, these would be the new types of metamaterials if one of the phases is replaced with metallic materials. In addition, when the particles were transformed into nanoporous materials, it would also be useful for catalytic or sensor applications due to their high surface-to-volume ration and unusual well-defined pore structures. Although the nanostructured particles have been used in many applications such as drug delivery system, sensing device, self-healing, and optoelectronic device, it remains a challenge to scale-up monodisperse structured particles, which enable to investigate systematically the optical and electrical properties of the BCP particles with novel nanostructures.

Until now, the structured BCP particles have been prepared by high-mechanical force such as homogenizer, or sonicator, resulting in a broad range of the particle size. Polydisperse particles with different morphology and chemical heterogeneity can result in poor reproducibility and a variable property of the particles per batch. Some groups reported to fabricate uniform BCP particles using microfluidic method by which the particle diameters are ranged from hundreds nanometer to tens micrometer (Wang et al., 2010; Abate et al., 2011; Kuehne and Weitz, 2011), while other groups reported to prepare the structured BCP particles using membrane device (Tanaka et al., 2009; Connal et al., 2012; Deng et al., 2013), which enable a large-scale production of the particles but broader size distribution of the particles than that using microfluidic method. Therefore, it remains a challenge to produce large-scale and monodisperse structured BCP particles at sub-micrometer scale for practical application as mentioned above.

\section{Acknowledgments}

We acknowledge financial support by Korean NRF grant (no. 2010-0029409, NRF-2014R1A2A2A01006628).

Bang, J., Kim, B. J., Stein, G. E., Russell, T. P., Li, X., Wang, J., et al. (2007). Effect of humidity on the ordering of PEO-based copolymer thin films. Macromolecules 40, 7019-7025. doi:10.1021/ma0710737

Bates, F. S., and Fredrickson, G. H. (1990). Block copolymer thermodynamics theory and experiment. Annu. Rev. Phys. Chem. 41, 525-557. doi:10.1146/ annurev.pc.41.100190.002521

Bita, I., Yang, J. K. W., Jung, Y. S., Ross, C. A., Thomas, E. L., and Berggren, K. K. (2008). Graphoepitaxy of self-assembled block copolymers on two-dimensional periodic patterned templates. Science 321, 939-943. doi:10.1126/science. 1159352

Bockstaller, M. R., Lapetnikov, Y., Margel, S., and Thomas, E. L. (2003). Sizeselective organization of enthalpic compatibilized nanocrystals in ternary block copolymer/particle mixtures. J. Am. Chem. Soc. 125, 5276-5277. doi:10.1021/ ja034523t

Bonnemann, H., Brinkmann, R., Britz, P., Endruschat, U., Mortel, R., Paulus, U. A., et al. (2000). Nanoscopic Pt-bimetal colloids as precursors for PEM fuel cell catalysts. J. New. Mater. Electrochem. Syst. 3, 199-206.

Boontongkong, Y., and Cohen, R. E. (2002). Cavitated block copolymer micellar thin films: lateral arrays of open nanoreactors. Macromolecules 35, 3647-3652. doi:10.1021/ma0117357 
Burlak, G., Diaz-de-Anda, A., and Zamudio-Lara, A. (2012). The narrow transmission peaks and field confinement produced by defects in a multilayered microsphere. Opt. Commun. 285, 1542-1549. doi:10.1016/j. optcom.2011.11.101

Campelo, J. M., Luna, D., Luque, R., Marinas, J. M., and Romero, A. A. (2009). Sustainable preparation of supported metal nanoparticles and their applications in catalysis. ChemSusChem 2, 18-45. doi:10.1002/cssc.200800227

Caruso, F., Caruso, R. A., and Mohwald, H. (1998a). Nanoengineering of inorganic and hybrid hollow spheres by colloidal templating. Science 282, 1111-1114. doi:10.1126/science.282.5391.1111

Caruso, F., Lichtenfeld, H., Giersig, M., and Mohwald, H. (1998b). Electrostatic selfassembly of silica nanoparticle - polyelectrolyte multilayers on polystyrene latex particles. J. Am. Chem. Soc. 120, 8523-8524. doi:10.1021/ja9815024

Caruso, F., and Mohwald, H. (1999). Preparation and characterization of ordered nanoparticle and polymer composite multilayers on colloids. Langmuir 15, 8276-8281. doi:10.1021/la990426v

Cavicchi, K. A., and Russell, T. P. (2007). Solvent annealed thin films of asymmetric polyisoprene-polylactide diblock copolymers. Macromolecules 40, 1181-1186. doi:10.1021/ma061163w

Chai, J., Wang, D., Fan, X. N., and Buriak, J. M. (2007). Assembly of aligned linear metallic patterns on silicon. Nat. Nanotechnol. 2, 500-506. doi:10.1038/nnano. 2007.227

Chang, C. C., and Lo, C. T. (2011). Effect of particles on the structure of solventannealed block copolymer/nanoparticle composite thin film. J. Phys. Chem. B 115, 2485-2493. doi:10.1021/jp109321j

Chi, P., Wang, Z., Li, B. H., and Shi, A. C. (2011). Soft confinement-induced morphologies of diblock copolymers. Langmuir 27, 11683-11689. doi:10.1021/ la202448c

Chiu, J. J., Kim, B. J., Kramer, E. J., and Pine, D. J. (2005). Control of nanoparticle location in block copolymers. J. Am. Chem. Soc. 127, 5036-5037. doi:10.1021/ ja050376i

Choi, S. J., Kim, M. P., Lee, S. J., Kim, B. J., and Kim, I. D. (2014). Facile Au catalyst loading on the inner shell of hollow $\mathrm{SnO}_{2}$ spheres using Au-decorated block copolymer sphere templates and their selective $\mathrm{H}_{2} \mathrm{~S}$ sensing characteristics. Nanoscale 6, 11898-11903. doi:10.1039/c4nr03706e

Chu, C. J., Chung, P. Y., Chi, M. H., Kao, Y. H., and Chen, J. T. (2014). Threedimensional block copolymer nanostructures by the solvent-annealing-induced wetting in anodic aluminum oxide templates. Macromol. Rapid Commun. 35, 1598-1605. doi:10.1002/marc.201400222

Connal, L. A., Lynd, N. A., Robb, M. J., See, K. A., Jang, S. G., Spruell, J. M., et al. (2012). Mesostructured block copolymer nanoparticles: versatile templates for hybrid inorganic/organic nanostructures. Chem. Mater. 24, 4036-4042. doi:10. $1021 / \mathrm{cm} 3011524$

Coustet, M., Irigoyen, J., Garcia, T. A., Murray, R. A., Romero, G., Cortizo, M. S., et al. (2014). Layer-by-layer assembly of polymersomes and polyelectrolytes on planar surfaces and microsized colloidal particles. J. Colloid Interface Sci. 421, 132-140. doi:10.1016/j.jcis.2014.01.038

Dauphas, N., van Zuilen, M., Wadhwa, M., Davis, A. M., Marty, B., and Janney, P. E. (2004). Clues from Fe isotope variations on the origin of early Archean BIFs from Greenland. Science 306, 2077-2080. doi:10.1126/science.1104639

Delcea, M., Mohwald, H., and Skirtach, A. G. (2011). Stimuli-responsive LbL capsules and nanoshells for drug delivery. Adv. Drug Deliv. Rev. 63, 730-747. doi:10.1016/j.addr.2011.03.010

Deng, R. H., Liang, F. X., Li, W. K., Yang, Z. Z., and Zhu, J. T. (2013). Reversible transformation of nanostructured polymer particles. Macromolecules 46, 7012-7017. doi:10.1021/ma401398h

Deng, R. H., Liu, S. Q., Liang, F. X., Wang, K., Zhu, J. T., and Yang, Z. Z. (2014). Polymeric Janus particles with hierarchical structures. Macromolecules 47, 3701-3707. doi:10.1021/ma500331w

Gourevich, I., Field, L. M., Wei, Z. X., Paquet, C., Petukhova, A., Alteheld, A., et al. (2006). Polymer multilayer particles: a route to spherical dielectric resonators. Macromolecules 39, 1449-1454. doi:10.1021/ma052167o

Grigoriev, D. O., Kohler, K., Skorb, E., Shchukin, D. G., and Mohwald, H. (2009). Polyelectrolyte complexes as a "smart" depot for self-healing anticorrosion coatings. Soft Matter 5, 1426-1432. doi:10.1039/b815147d

Guczi, L., Beck, A., Horvath, A., Koppany, Z., Stefler, G., Frey, K., et al. (2003). AuPd bimetallic nanoparticles on $\mathrm{TiO}_{2}$ : XRD, TEM, in situ EXAFS studies and catalytic activity in CO oxidation. J. Mol. Catal. A Chem. 204, 545-552. doi:10.1016/S1381-1169(03)00337-6
Hao, Q. H., Miao, B., Song, Q. G., Niu, X. H., and Liu, T. J. (2014). Phase behaviors of sphere-forming triblock copolymers confined in nanopores: a dynamic density functional theory study. Polymer 55, 4281-4288. doi:10.1016/j.polymer. 2014.06.062

Hawker, C. J., and Russell, T. P. (2005). Block copolymer lithography: merging “bottom-up" with “top-down” processes. MRS Bull. 30, 952-966. doi:10.1557/ mrs2005.249

Hayward, R. C., Chmelka, B. F., and Kramer, E. J. (2005). Crosslinked Poly(styrene)Block-Poly(2-vinylpyridine) thin films as swellable templates for mesostructured silica and titania. Adv. Mater. 17, 2591-2595. doi:10.1002/adma. 200500334

He, X., Zou, Z., Kan, D., and Liang, H. (2015). Self-assembly of diblock copolymer confined in an array-structure space. J. Chem. Phys. 142, 101912. doi:10.1063/1. 4907532

Higuchi, T., Motoyoshi, K., Sugimori, H., Jinnai, H., Yabu, H., and Shimomura, M. (2012). Three-dimensional observation of confined phase-separated structures in block copolymer nanoparticles. Soft Matter 8, 3791-3797. doi:10.1039/ c2sm07139h

Higuchi, T., Shimomura, M., and Yabu, H. (2013). Reorientation of microphaseseparated structures in water-suspended block copolymer nanoparticles through microwave annealing. Macromolecules 46, 4064-4068. doi:10.1021/ma400620v

Higuchi, T., Tajima, A., Motoyoshi, K., Yabu, H., and Shimomura, M. (2008). Frustrated phases of block copolymers in nanoparticles. Angew. Chem. Int. Ed. 47, 8044-8046. doi:10.1002/anie.200803003

Hou, P. L., Fan, H. L., and Jin, Z. X. (2015). Spiral and mesoporous block polymer nanofibers generated in confined nanochannels. Macromolecules 48, 272-278. doi: $10.1021 / \mathrm{ma} 501933 \mathrm{~s}$

Huang, E., Russell, T. P., Harrison, C., Chaikin, P. M., Register, R. A., Hawker, C. J., et al. (1998). Using surface active random copolymers to control the domain orientation in diblock copolymer thin films. Macromolecules 31, 7641-7650. doi:10.1021/ma980705+

Hudson, Z. M., Lunn, D. J., Winnik, M. A., and Manners, I. (2014). Colourtunable fluorescent multiblock micelles. Nat. Commun. 5, 1-8. doi:10.1038/ ncomms4372

Janczewski, D., Song, J., and Vancso, G. J. (2014). Colloidal, water soluble probes constructed with quantum dots and amphiphilic poly(ferrocenylsilane) for smart redox sensing. Eur. Polym. J. 54, 87-94. doi:10.1016/j.eurpolymj.2014. 02.012

Jang, S. G., Audus, D. J., Klinger, D., Krogstad, D. V., Kim, B. J., Cameron, A., et al. (2013). Striped, ellipsoidal particles by controlled assembly of diblock copolymers. J. Am. Chem. Soc. 135, 6649-6657. doi:10.1021/ ja4019447

Jang, S. G., Khan, A., Dimitriou, M. D., Kim, B. J., Lynd, N. A., Kramer, E. J., et al. (2011). Synthesis of thermally stable Au-Core/Pt-Shell nanoparticles and their segregation behavior in diblock copolymer mixtures. Soft Matter 7, 6255-6263. doi: $10.1039 / \mathrm{c} 1 \mathrm{sm} 05223 \mathrm{c}$

Jeon, S. J., Yang, S. M., Kim, B. J., Petrie, J. D., Jang, S. G., Kramer, E. J., et al. (2009) Hierarchically structured colloids of diblock copolymers and Au nanoparticles. Chem. Mater. 21, 3739-3741. doi:10.1021/cm9011124

Jeon, S. J., Yi, G. R., Koo, C. M., and Yang, S. M. (2007). Nanostructures inside colloidal particles of block copolymer/homopolymer blends. Macromolecules 40, 8430-8439. doi:10.1021/ma0712302

Jeon, S. J., Yi, G. R., and Yang, S. M. (2008). Cooperative assembly of block copolymers with deformable interfaces: toward nanostructured particles. $A d v$ Mater. 20, 4103-4108. doi:10.1002/adma.200801377

Jin, Z. X., and Fan, H. L. (2014). Self-assembly of nanostructured block copolymer nanoparticles. Soft Matter 10, 9212-9219. doi:10.1039/c4sm02064b

Jung, Y. S., and Ross, C. A. (2007). Orientation-controlled self-assembled nanolithography using a polystyrene-polydimethylsiloxane block copolymer. Nano Lett. 7, 2046-2050. doi:10.1021/nl0709241

Kane, R. S., Cohen, R. E., and Silbey, R. (1999). Synthesis of doped ZnS nanoclusters within block copolymer nanoreactors. Chem. Mater. 11, 90-93. doi:10.1021/ cm980468p

Kao, J., Thorkelsson, K., Bai, P., Zhang, Z., Sun, C., and Xu, T. (2014). Rapid fabrication of hierarchically structured supramolecular nanocomposite thin films in one minute. Nat. Commun. 5, 1-8. doi:10.1038/ncomms5053

Kim, B. J., Chiu, J. J., Yi, G. R., Pine, D. J., and Kramer, E. J. (2005). Nanoparticle-induced phase transitions in diblock-copolymer films. Adv. Mater 17,2618-2622. doi:10.1002/adma.200500502 
Kim, G., and Libera, M. (1998). Morphological development in solvent-cast polystyrene-polybutadiene-polystyrene (SBS) triblock copolymer thin films. Macromolecules 31, 2569-2577. doi:10.1021/ma971349i

Kim, M. P., Kang, D. J., Jung, D. W., Kannan, A. G., Kim, K. H., Ku, K. H., et al. (2012). Gold-decorated block copolymer microspheres with controlled surface nanostructures. ACS Nano 6, 2750-2757. doi:10.1021/nn300194z

Kim, M. P., Ku, K. H., Kim, H. J., Jang, S. G., Yi, G. R., and Kim, B. J. (2013). Surface intaglio nanostructures on microspheres of gold-cored block copolymer spheres. Chem. Mater. 25, 4416-4422. doi:10.1021/cm402868q

Kim, S. H., Misner, M. J., Yang, L., Gang, O., Ocko, B. M., and Russell, T. P. (2006). Salt complexation in block copolymer thin films. Macromolecules 39, 8473-8479. doi:10.1021/ma061170k

Klinger, D., Wang, C. X., Connal, L. A., Audus, D. J., Jang, S. G., Kraemer, S., et al. (2014). A facile synthesis of dynamic, shape-changing polymer particles. Angew. Chem. Int. Ed. 53, 7018-7022. doi:10.1002/anie.201400183

Koneripalli, N., Singh, N., Levicky, R., Bates, F. S., Gallagher, P. D., and Satija, S. K. (1995). Confined block-copolymer thin-films. Macromolecules 28, 2897-2904. doi: $10.1021 / \mathrm{ma} 00112 \mathrm{a} 041$

Korczagin, I., Hempenius, M. A., and Vancso, G. J. (2004). Poly(ferrocenyisilaneblock-methacrylates) via sequential anionic and atom transfer radical polymerization. Macromolecules 37, 1686-1690. doi:10.1021/ma0358172

Ku, K. H., Kim, M. P., Paek, K., Shin, J. M., Chung, S., Jang, S. G., et al. (2013). Multicolor emission of hybrid block copolymer-quantum dot microspheres by controlled spatial isolation of quantum dots. Small 9, 2667-2672. doi:10.1002/ smll.201202839

Ku, K. H., Shin, J. M., Kim, M. P., Lee, C. H., Seo, M. K., Yi, G. R., et al. (2014). Size-controlled nanoparticle-guided assembly of block copolymers for convex lens-shaped particles. J. Am. Chem. Soc. 136, 9982-9989. doi:10.1021/ja502075f

Ku, K. H., Yang, H., Shin, J. M., and Kim, B. J. (2015). Aspect ratio effect of nanorod surfactants on the shape and internal morphology of block copolymer particles. J. Polym. Sci. A Polym. Chem. 53, 188-192. doi:10.1002/pola.27333

Kuehne, A. J. C., and Weitz, D. A. (2011). Highly monodisperse conjugated polymer particles synthesized with drop-based microfluidics. Chem. Commun. 47, 12379-12381. doi:10.1039/c1cc14251h

Lambooy, P., Russell, T. P., Kellogg, G. J., Mayes, A. M., Gallagher, P. D., and Satija, S. K. (1994). Observed frustration in confined block-copolymers. Phys. Rev. Lett. 72, 2899-2902. doi:10.1103/PhysRevLett.72.2899

Landfester, K. (2001a). The generation of nanoparticles in miniemulsions. Adv. Mater. 13, 765-768. doi:10.1002/1521-4095(200105)13:10<765: AID-ADMA765>3.0.CO;2-F

Landfester, K. (2001b). Polyreactions in miniemulsions. Macromol. Rapid Commun. 22, 896-936. doi:10.1002/1521-3927(20010801)22:12<896::AID-MARC896>3. 3.CO;2-I

Landfester, K. (2006). Synthesis of colloidal particles in miniemulsions. Annu. Rev. Mater. Res. 36, 231-279. doi:10.1146/annurev.matsci.36.032905.091025

Landfester, K. (2009). Miniemulsion polymerization and the structure of polymer and hybrid nanoparticles. Angew. Chem. Int. Ed. 48, 4488-4507. doi:10.1002/ anie. 200900723

Landfester, K., and Mailander, V. (2013). Nanocapsules with specific targeting and release properties using miniemulsion polymerization. Expert Opin. Drug Deliv. 10, 593-609. doi:10.1517/17425247.2013.772976

Latnikova, A., Grigoriev, D., Schenderlein, M., Mohwald, H., and Shchukin, D. A. (2012). New approach towards "active" self-healing coatings: exploitation of microgels. Soft Matter 8, 10837-10844. doi:10.1039/c2sm26100f

Lee, J., Ryu, D. Y., and Cho, J. (2011). Temperature-pressure superposition in SANS chi for an A-b-B diblock copolymer. Macromolecules 44, 2387-2391. doi:10. 1021/ma102102x

Lee, S. Y., Kim, S. H., Kim, M. P., Jeon, H. C., Kang, H., Kim, H. J., et al. (2013a). Freestanding and arrayed nanoporous microcylinders for highly active 3D SERS substrate. Chem. Mater. 25, 2421-2426. doi:10.1021/cm400298e

Lee, J. P., Chen, D. C., Li, X. X., Yoo, S., Bottomley, L. A., El-Sayed, M. A., et al. (2013b). Well-organized raspberry-like Ag@Cu bimetal nanoparticles for highly reliable and reproducible surface-enhanced Raman scattering. Nanoscale 5, 11620-11624. doi:10.1039/c3nr03363e

Leventis, H. C., King, S. P., Sudlow, A., Hill, M. S., Molloy, K. C., and Haque, S. A. (2010). Nanostructured hybrid polymer-inorganic solar cell active layers formed by controllable in situ growth of semiconducting sulfide networks. Nano Lett. 10, 1253-1258. doi:10.1021/nl903787j
Li, L., Matsunaga, K., Zhu, J. T., Higuchi, T., Yabu, H., Shimomura, M., et al. (2010). Solvent-driven evolution of block copolymer morphology under 3D confinement. Macromolecules 43, 7807-7812. doi:10.1021/ma101529b

Li, L., Miesch, C., Sudeep, P. K., Balazs, A. C., Emrick, T., Russell, T. P., et al. (2011). Kinetically trapped co-continuous polymer morphologies through intraphase gelation of nanoparticles. Nano Lett. 11, 1997-2003. doi:10.1021/nl200366z

Li, W. H., Liu, M. J., Qiu, F., and Shi, A. C. (2013). Phase diagram of diblock copolymers confined in thin films. J. Phys. Chem. B 117, 5280-5288. doi:10.1021/ jp309546q

Li, W. H., and Wickham, R. A. (2006). Self-assembled morphologies of a diblock copolymer melt confined in a cylindrical nanopore. Macromolecules 39, 8492-8498. doi:10.1021/ma052151y

Li, W. H., Wickham, R. A., and Garbary, R. A. (2006). Phase diagram for a diblock copolymer melt under cylindrical confinement. Macromolecules 39, 806-811. doi:10.1021/ma052151y

Li, Z., Zhao, W., Liu, Y., Rafailovich, M. H., Sokolov, J., Khougaz, K., et al. (1996). Self-ordering of diblock copolymers from solution. J. Am. Chem. Soc. 118, 10892-10893. doi:10.1021/ja961713d

Lim, J., Yang, H., Paek, K., Cho, C. H., Kim, S., Bang, J., et al. (2011). "Click" synthesis of thermally stable au nanoparticles with highly grafted polymer shell and control of their behavior in polymer matrix. J. Polym. Sci. A Polym. Chem. 49, 3464-3474. doi:10.1002/pola.24782

Liu, R. C. (2014). Hybrid organic/inorganic nanocomposites for photovoltaic cells. Materials 7, 2747-2771. doi:10.3390/ma7042747

Lopes, W. A., and Jaeger, H. M. (2001). Hierarchical self-assembly of metal nanostructures on diblock copolymer scaffolds. Nature 414, 735-738. doi:10.1038/ $414735 \mathrm{a}$

Louage, B., Zhang, Q. L., Vanparijs, N., Voorhaar, L., Vande Casteele, S., Shi, Y., et al. (2015). Degradable ketal-based block copolymer nanoparticles for anticancer drug delivery: a systematic evaluation. Biomacromolecules 16, 336-350. doi:10. 1021/bm5015409

Lu, Y. F., Fan, H. Y., Stump, A., Ward, T. L., Rieker, T., and Brinker, C. J. (1999). Aerosol-assisted self-assembly of mesostructured spherical nanoparticles. Nature 398, 223-226. doi:10.1038/18410

Lv, L. P., Zhao, Y., Vilbrandt, N., Gallei, M., Vimalanandan, A., Rohwerder, M., et al. (2013). Redox responsive release of hydrophobic self-healing agents from polyaniline capsules. J. Am. Chem. Soc. 135, 14198-14205. doi:10.1021/ ja405279t

Ma, N., Zhang, H. Y., Song, B., Wang, Z. Q., and Zhang, X. (2005). Polymer micelles as building blocks for layer-by-layer assembly: an approach for incorporation and controlled release of water-insoluble dyes. Chem. Mater. 17, 5065-5069. doi:10.1021/cm051221c

MacLachlan, M. J., Ginzburg, M., Coombs, N., Coyle, T. W., Raju, N. P., Greedan, J. E., et al. (2000). Shaped ceramics with tunable magnetic properties from metal-containing polymers. Science 287, 1460-1463. doi:10.1126/science.287. 5457.1460

Mai, Y. Y., and Eisenberg, A. (2012). Self-assembly of block copolymers. Chem. Soc. Rev. 41, 5969-5985. doi:10.1039/c2cs35115c

Maiz, J., Zhao, W., Gu, Y., Lawrence, J., Arbe, A., Alegria, A., et al. (2014) Dynamic study of polystyrene-block-Poly(4-Vinylpyridine) copolymer in bulk and confined in cylindrical nanopores. Polymer 55, 4057-4066. doi:10.1016/j. polymer.2014.05.042

Malenfant, P. R., Wan, J., Taylor, S. T., and Manoharan, M. (2007). Self-assembly of an organic-inorganic block copolymer for nano-ordered ceramics. Nat. Nanotechnol. 2, 43-46. doi:10.1038/nnano.2006.168

Manners, I. (2001). Materials science - putting metals into polymers. Science 294, 1664-1666. doi:10.1126/science.1066321

Manners, I. (2007). Block copolymers with functional inorganic blocks: living addition polymerization of inorganic monomers. Angew. Chem. Int. Ed. 46, 1565-1568. doi:10.1002/anie.200604503

Marencic, A. P., and Register, R. A. (2010). Controlling order in block copolymer thin films for nanopatterning applications. Annu. Rev. Chem. Biomol. Eng. 1, 277-297. doi:10.1146/annurev-chembioeng-073009-101007

Mei, S. L., Feng, X. D., and Jin, Z. X. (2011). Fabrication of polymer nanospheres based on Rayleigh instability in capillary channels. Macromolecules 44 1615-1620. doi:10.1021/ma102573p

Mei, S. L., and Jin, Z. X. (2013). Mesoporous block-copolymer nanospheres prepared by selective swelling. Small 9, 322-329. doi:10.1002/smll.201201504 
Misner, M. J., Skaff, H., Emrick, T., and Russell, T. P. (2003). Directed deposition of nanoparticles using diblock copolymer templates. Adv. Mater. 15, 221-224. doi:10.1002/adma.200390050

Mokarian-Tabari, P., Cummins, C., Rasappa, S., Simao, C., Torres, C. M. S., Holmes, J. D., et al. (2014). Study of the kinetics and mechanism of rapid self-assembly in block copolymer thin films during solvo-microwave annealing. Langmuir 30, 10728-10739. doi:10.1021/la503137q

Nikoubashman, A., Register, R. A., and Panagiotopoulos, A. Z. (2014). Sequential domain realignment driven by conformational asymmetry in block copolymer thin films. Macromolecules 47, 1193-1198. doi:10.1021/ ma402526q

Okubo, M., Saito, N., Takekoh, R., and Kobayashi, H. (2005). Morphology of polystyrene/polystyrene-block-Poly(Methyl Methacrylate)/Poly(Methyl Methacrylate) composite particles. Polymer 46, 1151-1156. doi:10.1016/j. polymer.2004.11.057

Otsuka, H., Nagasaki, Y., and Kataoka, K. (2003). PEGylated nanoparticles for biological and pharmaceutical applications. Adv. Drug Deliv. Rev. 55, 403-419. doi:10.1016/S0169-409X(02)00226-0

Paek, K., Chung, S., Cho, C. H., and Kim, B. J. (2011). Fluorescent and pHresponsive diblock copolymer-coated core-shell CdSe/ZnS particles for a colordisplaying, ratiometric pH sensor. Chem. Commun. 47, 10272-10274. doi:10. 1039/c1cc13848k

Paek, K., Yang, H., Lee, J., Park, J., and Kim, B. J. (2014). Efficient colorimetric pH sensor based on responsive polymer-quantum dot integrated graphene oxide. ACS Nano 8, 2848-2856. doi:10.1021/nn406657b

Park, C., Yoon, J., and Thomas, E. L. (2003). Enabling nanotechnology with self assembled block copolymer patterns. Polymer 44, 6725-6760. doi:10.1016/j. polymer.2003.08.011

Pastoriza-Santos, I., Scholer, B., and Caruso, F. (2001). Core-shell colloids and hollow polyelectrolyte capsules based on diazoresins. Adv. Funct. Mater. 11, 122-128. doi:10.1002/1616-3028(200104)11:2<122::AID-ADFM122>3.3. $\mathrm{CO} ; 2-\mathrm{E}$

Petukhova, A., Paton, A. S., Wei, Z. X., Gourevich, I., Nair, S. V., Ruda, H. E., et al. (2008). Polymer multilayer microspheres loaded with semiconductor quantum dots. Adv. Funct. Mater. 18, 1961-1968. doi:10.1002/adfm.200701441

Peyratout, C. S., and Dahne, L. (2004). Tailor-made polyelectrolyte microcapsules: from multilayers to smart containers. Angew. Chem. Int. Ed. 43, 3762-3783. doi: $10.1002 /$ anie. 200300568

Pham, H. H., Gourevich, I., Oh, J. K., Jonkman, J. E. N., and Kumacheva, E. A. (2004). Multidye nanostructured material for optical data storage and security data encryption. Adv. Mater. 16, 516-520. doi:10.1002/chem. 201406384

Rahikkala, A., Soininen, A. J., Ruokolainen, J., Mezzenga, R., Raula, J., and Kauppinen, E. I. (2013). Self-assembly of PS-b-P4VP block copolymers of varying architectures in aerosol nanospheres. Soft Matter 9, 1492-1499. doi:10.1039/ C2SM26913A

Ramahi, O. M., Almoneef, T. S., Alshareef, M., and Boybay, M. S. (2012). Metamaterial particles for electromagnetic energy harvesting. Appl. Phys. Lett. 101, 173903. doi:10.1063/1.4764054

Rao, J. P., and Geckeler, K. E. (2011). Polymer nanoparticles: preparation techniques and size-control parameters. Prog. Polym. Sci. 36, 887-913. doi:10.1016/ j.progpolymsci.2011.01.001

Rivera Gil, P., del Mercato, L. L., del-Pino, P., Munoz-Javier, A., and Parak, W. J. (2008). Nanoparticle-modified polyelectrolyte capsules. Nano Today 3, 12-21. doi:10.1039/c4cp05231e

Robb, M. J., Connal, L. A., Lee, B. F., Lynd, N. A., and Hawker, C. J. (2012). Functional block copolymer nanoparticles: toward the next generation of delivery vehicles. Polym. Chem. 3, 1618-1628. doi:10.1039/c2py20131c

Shastri, A. G., and Schwank, J. (1985a). Metal dispersion of bimetallic catalysts via stepwise chemisorption and surface titration.1. Ru-Au/Sio2. J. Catal. 95, 271-283. doi:10.1016/0021-9517(85)90028-4

Shastri, A. G., and Schwank, J. (1985b). Metal dispersion of bimetallic catalysts via stepwise chemisorption and surface titration.2. Ru-Au/Mgo. J. Catal. 95, 284-288. doi:10.1016/0021-9517(85)90028-4

Shchukin, D. G., and Mohwald, H. (2006). Sonochemical nanosynthesis at the engineered interface of a cavitation microbubble. Phys. Chem. Chem. Phys. 8, 3496-3506. doi:10.1039/b606104d
Sheikholeslami, S. N., Alaeian, H., Koh, A. L., and Dionne, J. A. (2013). A Metafluid exhibiting strong optical magnetism. Nano Lett. 13, 4137-4141. doi:10.1021/ nl $401642 \mathrm{z}$

Smulders, W., and Monteiro, M. J. (2004). Seeded emulsion polymerization of block copolymer core-shell nanoparticles with controlled particle size and molecular weight distribution using xanthate-based RAFT polymerization. Macromolecules 37, 4474-4483. doi:10.1021/ma0494961

Sohn, B. H., and Seo, B. H. (2001). Fabrication of the multilayered nanostructure of alternating polymers and gold nanoparticles with thin films of selfassembling diblock copolymers. Chem. Mater. 13, 1752-1757. doi:10.1021/ cm000939j

Soukoulis, C. M., and Wegener, M. (2011). Past achievements and future challenges in the development of three-dimensional photonic metamaterials. Nat. Photonics 5, 523-530. doi:10.1038/nphoton.2011.154

Spatz, J., Mossmer, S., Moller, M., Kocher, M., Neher, D., and Wegner, G. (1998). Controlled mineralization and assembly of hydrolysis-based nanoparticles in organic solvents combining polymer micelles and microwave techniques. Adv. Mater. 10, 473-475. doi:10.1002/(SICI)1521-4095(199804)10:6<473:: AID-ADMA473>3.0.CO;2-Q

Sukhorukov, G., Fery, A., and Mohwald, H. (2005). Intelligent micro- and nanocapsules. Prog. Polym. Sci. 30, 885-897. doi:10.1016/j.progpolymsci.2005. 06.008

Sundberg, D. C., and Durant, Y. G. (2003). Latex particle morphology, fundamental aspects: a review. Polym. React. Eng. 11, 379-432. doi:10.1081/PRE-120024420

Tanaka, T., Saito, N., and Okubo, M. (2009). Control of layer thickness of onionlike multilayered composite polymer particles prepared by the solvent evaporation method. Macromolecules 42, 7423-7429. doi:10.1021/ma901100n

Tang, P., Qiu, F., Zhang, H. D., and Yang, Y. L. (2004). Morphology and phase diagram of complex block copolymers: ABC linear triblock copolymers. J. Phys. Chem. B 108, 8434-8438. doi:10.1021/jp037911q

Thomas, E. L., Reffner, J. R., and Bellare, J. (1990). A menagerie of interface structures in copolymer systems. J. Phys. Paris 51, C7363-C7374. doi:10.1051/ jphyscol:1990736

Tsutsumi, K., Funaki, Y., Hirokawa, Y., and Hashimoto, T. (1999). Selective incorporation of palladium nanoparticles into microphase-separated domains of Poly(2-vinylpyridine)-block-polyisoprene. Langmuir 15, 5200-5203. doi:10. 1021/la990246l

Vimalanandan, A., Lv, L. P., Tran, T. H., Landfester, K., Crespy, D., and Rohwerder, M. (2013). Redox-responsive self-healing for corrosion protection. Adv. Mater. 25, 6980-6984. doi:10.1002/adma.201302989

Wan, B. S., Liao, S. J., and Yu, D. R. (1999). Polymer-supported palladiummanganese bimetallic catalyst for the oxidative carbonylation of amines to carbamate esters. Appl. Catal. A Gen. 183, 81-84. doi:10.1016/S0926-860X(99) 00062-9

Wang, C. W., Oskooei, A., Sinton, D., and Moffitt, M. G. (2010). Controlled selfassembly of quantum dot-block copolymer colloids in multiphase microfluidic reactors. Langmuir 26, 716-723. doi:10.1021/la902427r

Wang, W., and Zhang, Q. (2012). Synthesis of block copolymer poly (NButyl Acrylate)-b-polystyrene by DPE seeded emulsion polymerization with monodisperse latex particles and morphology of self-assembly film surface. J. Colloid Interface Sci. 374, 54-60. doi:10.1016/j.jcis.2012.01.030

Wang, Y., Gosele, U., and Steinhart, M. (2008). Mesoporous block copolymer nanorods by swelling-induced morphology reconstruction. Nano Lett. 8, 3548-3553. doi:10.1021/nl8022687

Wang, Y. J., Hosta-Rigau, L., Lomas, H., and Caruso, F. (2011). Nanostructured polymer assemblies formed at interfaces: applications from immobilization and encapsulation to stimuli-responsive release. Phys. Chem. Chem. Phys. 13, 4782-4801. doi:10.1039/c0cp02287j

Whittell, G. R., Hager, M. D., Schubert, U. S., and Manners, I. (2011). Functional soft materials from metallopolymers and metallosupramolecular polymers. Nat. Mater. 10, 176-188. doi:10.1038/nmat2966

Winey, K. I., Gobran, D. A., Xu, Z. D., Fetters, L. J., and Thomas, E. L. (1994). Compositional dependence of the order-disorder transition in diblock copolymers. Macromolecules 27, 2392-2397. doi:10.1021/ma00087a005

Wu, Y. Y., Cheng, G. S., Katsov, K., Sides, S. W., Wang, J. F., Tang, J., et al. (2004). Composite mesostructures by nano-confinement. Nat. Mater. 3, 816-822. doi:10.1038/nmat1230 
Xiang, H. Q., Shin, K., Kim, T., Moon, S. I., McCarthy, T. J., and Russell, T. P. (2004). Block copolymers under cylindrical confinement. Macromolecules 37, 5660-5664. doi:10.1021/ma049299m

Xiong, X. P., Eckelt, J., Zhang, L., and Wolf, B. A. (2009). Thermodynamics of block copolymer solutions as compared with the corresponding homopolymer solutions: experiment and theory. Macromolecules 42, 8398-8405. doi:10.1021/ ma9014615

Xu, J., Wang, K., Li, J., Zhou, H., Xie, X., and Zhu, J. (2015). ABC triblock copolymer particles with tunable shape and internal structure through $3 \mathrm{D}$ confined assembly. Macromolecules 48, 2628-2636. doi:10.1021/acs.macromol.5b00335

Xu, T., Hawker, C. J., and Russell, T. P. (2005). Interfacial interaction dependence of microdomain orientation in diblock copolymer thin films. Macromolecules 38, 2802-2805. doi:10.1021/ma048005u

Xu, Y. C., Li, W. H., Qiu, F., and Lin, Z. Q. (2014). Self-assembly of 21-arm starlike diblock copolymer in bulk and under cylindrical confinement. Nanoscale 6 , 6844-6852. doi:10.1039/c4nr01275e

Yabu, H. (2013). Self-organized precipitation: an emerging method for preparation of unique polymer particles. Polym. J. 45, 261-268. doi:10.1038/pj. 2012.151

Yabu, H., Higuchi, T., and Shimomura, M. (2005). Unique phase-separation structures of block-copolymer nanoparticles. Adv. Mater. 17, 2062-2065. doi:10. 1002/adma.200500255

Yan, Y., Bjonmalm, M., and Caruso, F. (2014). Assembly of layer-by-layer particles and their interactions with biological systems. Chem. Mater. 26, 452-460. doi:10. $1021 / \mathrm{cm} 402126 \mathrm{n}$

Yang, H., Paek, K., and Kim, B. J. (2013). Efficient temperature sensing platform based on fluorescent block copolymer-functionalized graphene oxide. Nanoscale 5, 5720-5724. doi:10.1039/c3nr01486j

Yang, J., You, J. B., Chen, C. C., Hsu, W. C., Tan, H. R., Zhang, X. W., et al. (2011). Plasmonic polymer tandem solar cell. ACS Nano 5, 6210-6217. doi:10.1021/ nn202144b

Yang, R. Q., Li, B. H., and Shi, A. C. (2012). Phase behavior of binary blends of diblock copolymer/homopolymer confined in spherical nanopores. Langmuir 28, 1569-1578. doi:10.1021/la204449x

Yoo, M., Kim, S., Lim, J., Kramer, E. J., Hawker, C. J., Kim, B. J., et al. (2010). Facile synthesis of thermally stable core-shell gold nanoparticles via photocross-linkable polymeric ligands. Macromolecules 43, 3570-3575. doi:10.1021/ ma1000145

Yu, B., Li, B. H., Jin, Q. H., Ding, D., and Shi, A. C. (2007). Self-assembly of symmetric diblock copolymers confined in spherical nanopores. Macromolecules 40, 9133-9142. doi:10.1021/ma071624t

Yu, B., Sun, P. C., Chen, T. H., Jin, Q. H., Ding, D. T., Li, B. H., et al. (2006). Confinement-induced novel morphologies of block copolymers. Phys. Rev. Lett. 96, 138306. doi:10.1103/PhysRevLett.96.138306

Yu, H. Z., Qiu, X. Y., Nunes, S. P., and Peinemann, K. V. (2014). Biomimetic block copolymer particles with gated nanopores and ultrahigh protein sorption capacity. Nat. Commun. 5, 1-10. doi:10.1038/ncomms5110
Zhang, K., Gao, L., Chen, Y. M., and Yang, Z. Z. (2008a). Onionlike spherical polymer composites with controlled dispersion of gold nanoclusters. Chem. Mater. 20, 23-25. doi:10.1021/cm7028118

Zhang, K., Yu, X. L., Gao, L., Chen, Y. M., and Yang, Z. Z. (2008b). Mesostructured spheres of organic/inorganic hybrid from gelable block copolymers and arched nano-objects thereof. Langmuir 24, 6542-6548. doi:10.1021/la800096w

Zhang, K., Gao, L., Chen, Y. M., and Yang, Z. Z. (2010a). Onion-like microspheres with tricomponent from gelable triblock copolymers. J. Colloid Interface Sci. 346, 48-53. doi:10.1016/j.jcis.2010.02.039

Zhang, X. J., Harris, K. D., Wu, N. L. Y., Murphy, J. N., and Buriak, J. M. (2010b). Fast assembly of ordered block copolymer nanostructures through microwave annealing. ACS Nano 4, 7021-7029. doi:10.1021/nn102387c

Zhang, M. F., Yang, L., Yurt, S., Misner, M. J., Chen, J. T., Coughlin, E. B., et al. (2007). Highly ordered nanoporous thin films from cleavable polystyrene-blockpoly(ethylene oxide). Adv. Mater. 19, 1571-1576. doi:10.1002/adma.200602461

Zhang, X., Wang, L., Zhang, L., Lin, J., and Jiang, T. (2015a). Controllable hierarchical microstructures self-assembled from multiblock copolymers confined in thin films. Langmuir 31, 2533-2544. doi:10.1021/la503985u

Zhang, T., Deng, H., Yang, T., and Li, W. (2015b). Defective morphologies kinetically formed in diblock copolymers under the cylindrical confinement. Polymer 65, 168-174. doi:10.1016/j.polymer.2015.03.059

Zhao, B., Haasch, R. T., and MacLaren, S. (2004). Solvent-induced self-assembly of mixed Poly(methyl methacrylate)/polystyrene brushes on planar silica substrates: molecular weight effect. J. Am. Chem. Soc. 126, 6124-6134. doi:10.1021/ ja049570f

Zhao, Y., Thorkelsson, K., Mastroianni, A. J., Schilling, T., Luther, J. M., Rancatore, B. J., et al. (2009). Small-molecule-directed nanoparticle assembly towards stimuli-responsive nanocomposites. Nat. Mater. 8, 979-985. doi:10. $1038 /$ nmat 2565

Zoetebier, B., Hempenius, M. A., and Vancso, G. J. (2015). Redox-responsive organometallic hydrogels for in situ metal nanoparticle synthesis. Chem. Commun. 51, 636-639. doi:10.1039/c4cc06988a

Zuo, Y. X., Wang, G. Q., Yu, Y., Zuo, C. C., Shi, L. Y., Shi, F. L., et al. (2015). Phase behavior of copolymers confined in multi-walled nanotubes: insights from simulations. Polymers (Basel) 7, 120-133. doi:10.3390/polym7010120

Conflict of Interest Statement: The authors declare that the research was conducted in the absence of any commercial or financial relationships that could be construed as a potential conflict of interest.

Copyright (c) $2015 \mathrm{Kim}$ and Yi. This is an open-access article distributed under the terms of the Creative Commons Attribution License (CC BY). The use, distribution or reproduction in other forums is permitted, provided the original author(s) or licensor are credited and that the original publication in this journal is cited, in accordance with accepted academic practice. No use, distribution or reproduction is permitted which does not comply with these terms. 